\title{
ISOLATED ATRIOVENTRICULAR DISCORDANCE WITH SOLITUS VISCERA, INVERTED ATRIA, D-LOOP VENTRICLES, AND SOLITUS NORMALLY RELATED GREAT ARTERIES: REPORT OF A RARE CASE WITH SUCCESSFUL SURGICAL MANAGEMENT
}

Hideto Shimpo, MD, PhD, Kazuhiro Tani, MD, PhD, Iwao Hioki, MD, PhD, Yoichiro Miyake, MD, Koji Onoda, MD, PhD, Hidetoshi Hayakawa, MD, and Isao Yada, MD, PhD, Tsu, Mie, Japan

Congenital cardiac malformation with discordant atrioventricular and concordant ventriculoarterial alignments (isolated atrioventricular discordance) is rare. ${ }^{1-3}$ Only 29 cases of this defect have been reported. ${ }^{4}$ We report the case of an infant with isolated atrioventricular discordance and complete common atrioventricular canal. To our knowledge, this case is the first successful surgical repair without atrioventricular block for isolated atrioventricular discordance with complete common atrioventricular canal. ${ }^{1}$

From the Department of Thoracic and Cardiovascular Surgery and Department of Pediatrics, Mie University, School of Medicine, Tsu, Mie, Japan.

Received for publication Aug 10, 1998; accepted for publication Sept 17, 1998.

Address for reprints: Hideto Shimpo, MD, PhD, Department of Thoracic and Cardiovascular Surgery, Mie University, School of Medicine, 2-174 Edobashi, Tsu, Mie, Japan 5148507.

J Thorac Cardiovasc Surg 1999;117:393-4

Copyright (C) 1999 by Mosby, Inc.

0022-5223/99 $\$ 8.00+0 \quad \mathbf{1 2 / 5 4 / 9 4 6 4 2}$
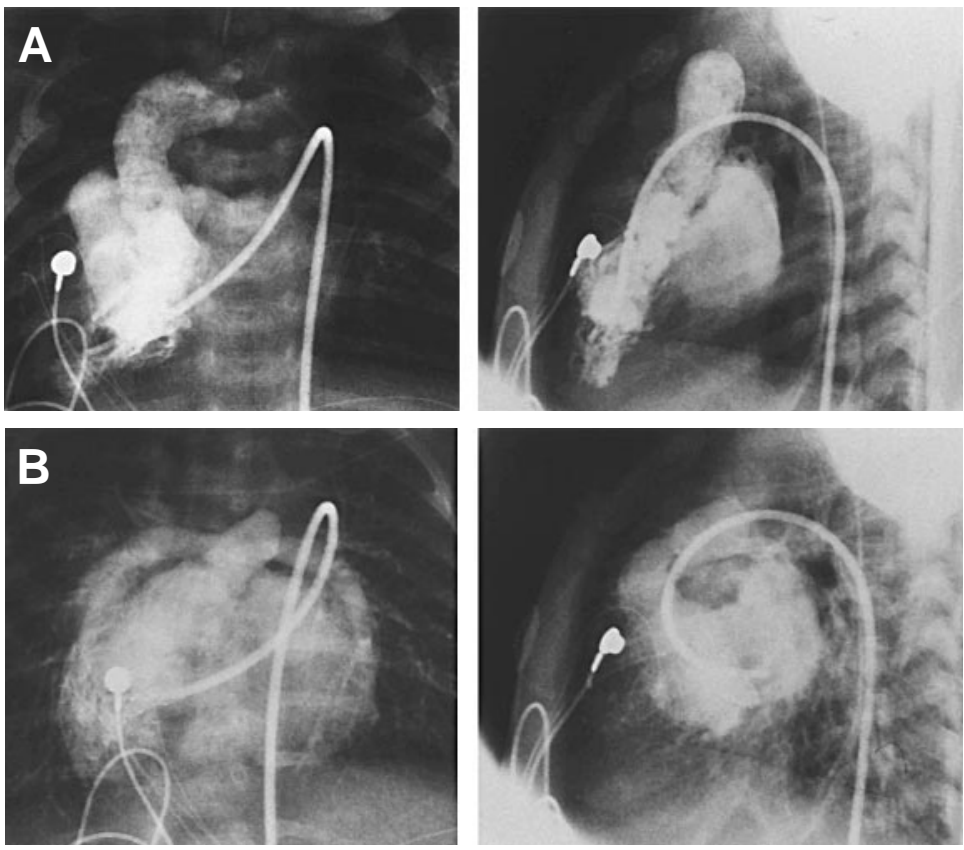

Fig 1. Preoperative angiography. A, Preoperative left ventriculography. Left ventriculography shows severe atrioventricular valve regurgitation. B, Preoperative right ventriculography.
Clinical summary. The patient was an 8-month-old girl, weighing $3.7 \mathrm{~kg}$, with poor physical development. She was a 2798-gm baby of a full-term pregnancy complicated by fetal bradycardia. Immediately after birth, she required pacemaker implantation because of sick sinus syndrome. Four months later she was noted to have congestive heart failure and was readmitted for treatment. Radiographic examination showed a left-sided stomach bubble, indicating visceral situs solitus, dextrocardia with marked cardiac enlargement, and increased vascular markings. Echocardiography showed isolated atrioventricular discordance and complete atrioventricular canal (Rastelli type A), with severe mitral and tricuspid valve regurgitation. Cardiac catheterization and angiography revealed interrupted inferior vena cava. The left-sided right atrium opened into the left-sided left ventricle and to the aorta. The left atrium was connected with a right-sided right ventricle. The pulmonary valve was leftward, anterior, and superior to the aortic valve; however, the left ventricle was anterior and to the left, with the right ventricle posterior and to the right. Systolic pressures were equal in both ventricles and in the aorta. There was a partial anomalous pulmonary 

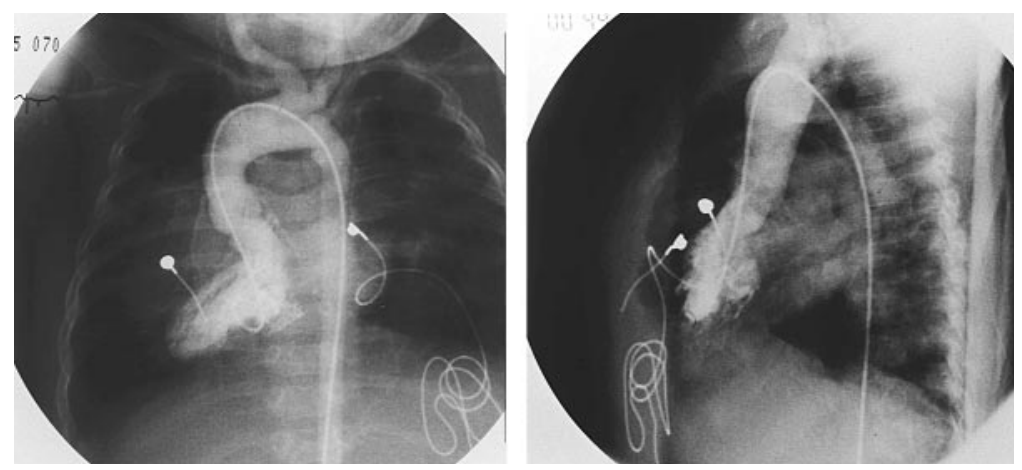

Fig 2. Postoperative left ventriculography shows no shunt between left ventricle and right ventricle and mild mitral regurgitation.

venous return, with the left pulmonary veins connecting with the left-sided right atrium.

Definitive repair was undertaken with moderate hypothermia and cardiopulmonary bypass. During the operation cardiac anatomy was confirmed. The atrial septum was entirely removed. A complete common atrioventricular canal was present. The anterior and posterior atrioventricular leaflets were approximated with interrupted sutures. To close the ventricular septal defect (VSD), a polytetrafluoroethylene sheet was trimmed distinctly larger than the size of the defect. Interrupted sutures were inserted between this polytetrafluoroethylene sheet and the new mitral anulus. The VSD was closed from the left ventricular side through left-sided right atrium. Then interrupted sutures with pledgets were inserted to close the VSD, far from the crest of VSD. To avoid heart block, sutures were skipped around the predicted area of the bundle and the posterior corner of the defect. An atrial baffle of pericardium was sutured into position in a way similar to that used in a Mustard operation. Bypass was discontinued without difficulty. The postoperative course was uneventful. The electrocardiogram showed atrial pacing rhythm without block. Postoperative angiography demonstrated no residual shunt between the ventricles and mild mitral regurgitation.

Discussion. In "isolated atrioventricular discordance," ventriculoarterial discordance is absent, by definition. ${ }^{3,5}$ Because there is only one intersegmental discordance (at the atrioventricular junction), physiologic and anatomic correction of the circulations can be achieved by an atrial switch procedure of the Mustard or Senning type. The diagnosis of isolated atrioventricular discordance connotes that an atrial switch procedure is indicated. In hearts with the heterotaxy syndromes of asplenia and polysplenia, we think that one should endeavor to diagnose the type of atrial situs. Our patient may well have the polysplenia syndrome, this being suggested by the presence of visceroatrial discordance (solitus viscera and inverted atria), interruption of the inferior vena cava, and a prominent azygos vein draining into the left superior vena cava. Angiography showed visceral situs and left-sided left ventricle. Therefore "isolated ventricular inversion" does not apply in our case.

Many patients with isolated atrioventricular discordance had a VSD. ${ }^{4}$ The course of the cardiac conduction system has not been elucidated in this particular segmental combination. A review of the literature suggests that the risk of postoperative atrioventricular block is quite high. Whenever possible, the VSD should be closed from the right ventricular side. However, in our case, the VSD was not approachable through a rightsided infundibulotomy, in part because of coexistence of a common atrioventricular canal. Therefore we closed the atrioventricular canal type of VSD from the left ventricular side, without block, using a left-sided transright atrial approach.

\section{REFERENCES}

1. Hazan E, Baillot F, Rey C, Dupuis C. Isolated ventricular discordance and complete atrioventricular canal in situs inversus. Am J Cardiol 1977;40:463-6.

2. Clarkson PM, Brandt PW, Barratt-Boyes BG, Neutze JM. "Isolated atrial inversion": visceral situs solitus, viscero atrial discordance, discordant ventricular D-loop without transposition, dextrocardia: diagnosis and surgical correction. Am J Cardiol 1972;29:877-81

3. Ostermeyer J, Bircks W, Krian A, Sievers G, Hilgenberg F. Isolated atrioventricular discordance: report of two surgical cases with isolated ventricular inversion. J Thorac Cardiovasc Surg 1983;86:926-9.

4. McElhinney DB, Reddy VM, Silverman NH, Hanley FL. Intraatrial baffle repair of isolated ventricular inversion with left atrial isomerism. Ann Thorac Surg 1996;62:1529-32.

5. Pasquini L, Sanders SP, Parness I, Colan S, Keane JF, Mayer JE, et al. Echocardiographic and anatomic findings in atrioventricular discordance with ventriculoarterial concordance. Am J Cardiol 1988;62:1256-62. 